\title{
O pragmatismo em Kaiser e Ranganathan e o pioneirismo na construção do método analítico-sintético
}

\author{
El pragamatismo en Kaiser y Ranganathan y los pioneros del método analítico sintético
}

Kaiser's and Ranganathan's pragmatism and the peoners of the analytic-sinthetic method

Rodrigo de SALES (1), José Augusto Chaves Guimarães (2)

(1) Departamento de Ciência da Informação da Universidade Federal Fluminense (UFF), Niterói, RJ, Brazil

(2) Departamento de Ciência da Informação da Universidade Estadual Paulista (UNESP), Marília, SP. Brasil guima@marilia.unesp.br; rodrigosales@vm.uff.br

\begin{abstract}
Resumen
Se examina la figura de Julius Kaiser como un referencial teórico pionero del tratamiento temático de la información (TTI) a partir de la hipótesis de que, al preparar su indización sistemática, Kaiser concibió los pilares iniciales del método analítico-sintético, que, a su vez, sirvieron de base para el desarrollo la teoría de la clasificación facetas de Ranganathan. Adoptando como enfoque metodológico el pragmatismo de William James, se investiga cómo el método procesual de indización de Kaiser puede consierarse como un precursor del método analítico-sintético. Se analizan las dimensiones analíticas y sintéticas del método de indización de Kaiser y se investiga hasta qué punto pudieron servir de base al de Ranganatan y cómo se contraponen ambos métodos entre sí.
\end{abstract}

Palabras clave: Julius Otto Kaiser. S. R. Ranganathan. Tratamiento temático de la información. Indización sistemática. Método analítico-sintético.

\section{Introdução}

A organização da informação, enquanto área de estudo que integra a Ciência da Informação, é constituída por duas dimensões: a dimensão descritiva (voltada aos elementos relativos às questões formais dos documentos) e a dimensão temática (voltada aos conteúdos informacionais). O foco do presente estudo está voltado à dimensão temática, denominada por Foskett (1973) como Tratamento Temático da Informação (TTI).

À título de esclarecimento, vale destacar que, dentre as diversas abordagens que formam 0 arcabouço teórico do TTI, o presente trabalho centra atenção ao desenvolvimento teóricometodológico da classificação bibliográfica e da indexação de assuntos.

Nesse contexto, merece relevo a indexação sistemática preconizada pelo bibliotecário alemão Julius Otto Kaiser (1868-1927). Preocupa-

\begin{abstract}
Considering that Julius Kaiser's Systematic Indexing brought pioneer contributions to the theoretical framework of the subject approach to information, this paper retrieves the foundations of the analiticalsynthetic method conceived by Kaiser which acted as a basis for Ranganathan's faceted theory. In this sense, and by adopting William James' pragmatism as a methodological approach, it analyzes the analitical and sintetic dimensions of Kaiser's indexing method and in what extent they act as a basis for the definition of Ranganathan's method, as well as how both Kaiser's and Raganathan's methods dialogue each other.
\end{abstract}

Keywords: Julius Otto Kaiser. S. R. Ranganathan. Subject Approach to information. Systematic indexing. Analytical-synthetic methods.

do em sistematizar a indexação de documentos por assunto em ambientes especializados (indústria, comércio, arquivos e bibliotecas especializadas), Kaiser desenvolveu uma nova forma de tratar tematicamente a informação. Para alcançar tal sistematização, Kaiser trouxe ao universo do TTI elementos teóricos fundamentais que, conforme será demonstrado neste trabalho, serviram de base para a construção do método analítico-sintético.

Fundamentada em uma organização do conhecimento que se pautava nas facetas que compunham os diversos assuntos, a teoria da classificação facetada, desenvolvida por Ranganathan a partir da década de 1930, figura no campo do TTI como uma das principais bases teóricas para a classificação de assuntos. A mencionada teoria ranganathiana amadureceu metodologicamente quando seu autor, ao longo de anos de aperfeiçoamento da própria teoria e do sistema que Ihe deu origem (Colon Classifica- 
tion), adotou um método baseado na análise (decomposição) e síntese (recomposição) dos assuntos dos documentos. Esse método "analítico-sintético" alcançou merecida notoriedade no âmbito internacional do TTI e tornou-se base fundamental para o quadro teórico da Biblioteconomia e da Ciência da Informação. Porém, conforme afirmação antecipada, mas não aprofundada, por Svenonius (2000), Kaiser teria sido o precursor do movimento analítico-sintético, ao passo que Ranganathan figuraria como o principal disseminador de tal método. Nesse sentido, investigam-se, aqui, os elementos fundamentais que podem consolidar ou, ao menos, apontar Kaiser como o pioneiro no método analíticosintético.

Os trabalhos desenvolvidos por Kaiser no início do Século XX (The card system at the office, 1908; Systematic Indexing, 1911), em unidades de informações norte-americanas e britânicas de escopos especializados e comerciais, foram realizados em uma conjuntura, permeada pelo pensamento pragmatista que ganhava força nos Estados Unidos ao final do Século XIX. Não há como precisar o quanto essa escola de especulação filosófica, chamada pragmatismo, liderada por Charles Sanders Peirce, William James e Olivier Wendell Holmes Jr., pode ter influenciado as diversas ambiências profissionais da época de Kaiser. Porém, não é difícil notar na literatura relativa à organização da informação, especialmente a bibliografia produzida por ingleses e americanos, uma tendência pragmática de desenvolvimento de produtos e construção de instrumentos voltados à eficiência funcional das unidades de informação.

Uma vez que o desenvolvimento do TTI de vertente anglo-americana, na qual se inserem os trabalhos de Kaiser e Ranganathan, é constantemente identificado como de caráter pragmáti$\mathrm{co}$, respalda-se metodologicamente a presente pesquisa no pragmatismo definido por William James, cujo foco recai nos caminhos percorridos e nas possibilidades de realizações teóricas.

A observação pragmática foi respaldada empiricamente pela análise das obras de Kaiser, que consistem no corpus fundamental da investigação. As dimensões analítica e sintética extraídas das obras de Kaiser possibilitaram a definição dos elementos fundamentais (pontos de observação desta pesquisa) utilizados para relacionar o método do bibliotecário alemão com o método de Ranganathan. Baseado em tais pontos de observação (elementos da análise, realização da análise, realização da síntese e produtos da síntese), o estudo demonstra os aspectos que podem fazer de Kaiser o precursor do método analítico-sintético.

\section{O pragmatismo de William James: uma possibilidade metodológica}

Por se tratar de um estudo de reflexão teórica, a presente pesquisa tem como pressuposto metodológico um método que sirva a uma abordagem, um modo de olhar um objeto (fenômeno). Ou seja, uma abordagem que norteia as reflexões tecidas a respeito da indexação sistemática de Kaiser e do método analítico-sintético de Ranganathan, focada nos caminhos desenvolvidos por ambos os bibliotecários, de modo que possibilite compreender e explorar os aspectos que os unem. Desse modo, o que se apresenta aqui como possibilidade metodológica é uma abordagem capaz de nortear, de modo pertinente, a leitura crítica a respeito das formas de tratamento temático de Kaiser e de Ranganathan, bem como respaldar as argumentações que serão construídas.

Ao dissertar a respeito das diversas possibilidades de conhecimento, Johannes Hessen, no livro Teoria do Conhecimento, afirma que "o pragmatismo abandona o conceito de verdade no sentido da concordância entre o pensamento e o ser" (Hessen, 1987, p. 50). Porém, esse abandono não se figura como no ceticismo (que nega a possibilidade de conhecimento ou de verdade) mas, sim, como uma proposta de um novo conceito de 'verdade': "verdadeiro significa útil, valioso, fomentador da vida" (Hessen, 1987, p. 51). "O homem não é fundamentalmente um ser teórico ou pensante mas, sim, um ser prático, um ser de vontade e de ação" (idem). O caráter da intelectualidade humana serve não para tomar conhecimento da verdade, mas sim para o homem se orientar na realidade, guiado por sua vontade e ação. O sentido e o valor do conhecimento estão no seu destino prático.

A sua verdade consiste na congruência dos pensamentos com os fins práticos do homem, em que aqueles resultem úteis e proveitosos para o comportamento prático deste (Hessen, 1987, p. 51).

Segundo Hessen (1987) e Abbagnano (1998), o termo pragmatismo foi cunhado na Filosofia em 1898 pelo filósofo norte-americano William James (1842-1910). Mas, como o próprio James ressalta na Segunda Conferência de seu livro 'Pragmatismo', as ideias do pragmatismo já estavam presentes no texto How to Make our Ideas Clear, publicado por Charles S. Peirce em 1878. Para James (2006), o termo pragmatismo, derivação da mesma palavra grega que significa ação (gênese das palavras prática e prático), foi introduzido efetivamente na Filosofia por Peirce 
em 1878, quando da publicação do mencionado artigo, no Popular Science Monthly. Essa versão tocante à origem da palavra pragmatismo é também encontrada em Lalande (1999) e em Blau (2006), quem afirma que o termo foi inventado por Peirce e popularizado por James. Historiadores da Filosofia, como Bertrand Russell, entre outros, são contundentes ao afirmarem que W. James divide o protagonismo do pragmatismo com Charles S. Peirce e com John Dewey, quem posteriormente adotou a denominação instrumentalismo.

Em uma perspectiva mais abrangente, sem empenhar esforços para distinguir o pragmatismo metafísico do pragmatismo metodológico, como o fez Peirce (Hessen, 1987; Abbagnano, 1998), ou ainda, sem detalhar a ligação do pragmatismo com a abordagem externalista, como pode ser encontrado em Dutra (2008), adota-se neste estudo a definição de James (2006, p. 44), para quem

[...] o método pragmático é, primariamente, um método de assentar disputas metafísicas que, de outro modo, se estenderiam interminavelmente [...] O método pragmático nesses casos é tentar interpretar cada noção traçando as suas consequências práticas respectivas

Nessa ótica, o pragmatismo de James se afasta dos 'hábitos' do racionalismo e se aproxima dos 'hábitos' do empirismo. Recorrendo às palavras do próprio filósofo (James, 2006, p. 47),

O pragmatista volta as costas resolutamente e de uma vez por todas a uma série de hábitos inveterados, caros aos filósofos profissionais. Afasta-se da abstração e da insuficiência, das soluções verbais, das más razões a priori, dos princípios firmados, dos sistemas fechados, com pretensões ao absoluto e às origens. Volta-se para o concreto e o adequado, para os fatos, a ação e o poder. O que significa o reinado do temperamento empírico e o descrédito sem rebuços do temperamento racionalista. O que significa ar livre e possibilidades da natureza, em contraposição ao dogma, à artificialidade e à pretensão de finalidade na verdade.

Nesses termos, James 'coloca uma pedra' em qualquer pretensão de resultados especiais ou de verdades absolutas e define o pragmatismo não como uma teoria mas, sim, como um método. Citando o pragmatista Papini, James (2006) explica o método pragmático por meio da seguinte analogia: imagine-se o corredor de um hotel que liga inúmeros quartos, sendo o corredor o método pragmático e os quartos as teorias. Nos quartos, teóricos, das mais variadas naturezas, definem e desenvolvem suas teorias. $\mathrm{Na}$ medida em que eles desejarem um meio prático de sair e retornar aos seus respectivos aposentos, para efetivamente obterem contato com o mundo concreto, é necessário percorrer o corredor do hotel. Nesse sentido, é possível visualizar que o pragmatismo está no meio das teorias, figurando-se como uma ligação das teorias com o mundo externo, caracterizandose, assim, como "possibilidade de realização", como caminho possível para acessar aos conhecimentos.

É sob essa perspectiva de pragmatismo enquanto método, enquanto caminho, enquanto "corredor de hotel", que a presente pesquisa lança olhar sobre os métodos desenvolvidos por Kaiser e por Ranganathan. Melhor dizendo, são os caminhos percorridos por ambos, ao tecerem suas respectivas formas de tratamento temático da informação, que serão focos da presente investigação.

No âmbito do TTI, nota-se uma constante busca pela determinação de caminhos (métodos) que viabilizem o tratamento mais adequado para a recuperação mais eficiente, ou seja, uma abordagem, pode-se afirmar, metodologicamente pragmática. Desse modo, um olhar pragmático sobre os métodos de Kaiser e de Ranganathan pode revelar elementos pioneiros no caminho percorrido por aquele com relação a esse último. Portanto, esta pesquisa não se configura em uma comparação entre o sistema de Kaiser e a classificação de Ranganathan mas, sim, em uma análise pragmática dos caminhos percorridos por Kaiser, buscando evidenciá-los como precursores dos caminhos trilhados por Ranganathan, quando da elaboração do método analítico-sintético.

\section{A dimensão analítica de Kaiser}

Para dissertar a respeito da dimensão analítica em Kaiser, é necessário retomar a noção exata do universo que o bibliotecário alemão se propôs a analisar. O universo analisado por Kaiser foi a literatura especializada, mais especificamente, a business literature - literatura veiculada no curso de qualquer negócio (comercial, técnico ou profissional). Kaiser entendia por literatura o registro descritivo do que se observava e se raciocinava a respeito de algo. Era o resultado da observação das coisas e da tradução dessa observação em uma dada língua. Portanto, a literatura, enquanto materialização da observação humana, era, para Kaiser, constituída por registros que funcionavam como representantes de conhecimentos e como fornecedores de informações. Tais registros, nesse contexto, estariam materializados nos documentos (ou materiais, como preferia Kaiser). Desse modo, os registros fixados pela literatura especializada eram representantes de conhecimen- 
tos especializados, materializados, por sua vez, em documentos de caráter específicos.

Se analisar, numa concepção aristotélica, consiste em decompor uma coisa composta em seus elementos mais simples e, numa perspectiva cartesiana, consiste em decompor um todo em suas partes, analisar a literatura especializada consistia, portanto, em tratá-la com base em seus elementos constituintes, ou seja, com base nos representantes de conhecimentos ali registrados. A perspectiva a partir da qual a literatura foi analisada por Kaiser não era nem gramatical (baseada nos vários tipos de palavras, suas relações, seus usos e combinações) nem lógica (baseada nas várias formas de raciocínio). Era uma perspectiva baseada no conhecimento e na informação transmitidos pela linguagem escrita nos documentos. Analisar sob essa perspectiva era, portanto, decompor a literatura especializada em seus elementos (registros) fundamentais, fornecedores de conhecimento e/ou informação.

Retomado o universo analisado por Kaiser - a literatura técnica/especializada - e o ponto de vista sob o qual ele se propôs a analisá-lo perspectiva do conhecimento e da informação -, cabe mostrar em que aspecto, necessariamente, Kaiser se valeu da noção aristotélica de categorização. Para nortear a identificação dos elementos informativos fundamentais presentes na literatura, concepção também de Otlet, Kaiser, diferentemente daquele, propôs a categorização dos discursos, a categorização dos assuntos veiculados pela literatura.

Categorias, para Kaiser (1908, 1911), consistiam nas partes de um discurso registrado que revelavam os elementos de conhecimento de um assunto, em sua dimensão estática (concreto) e dinâmica (processo). Para analisar um assunto de um documento era necessário, portanto, identificar em seu conteúdo os registros de conhecimento que correspondiam aos concretos e os registros que dizem respeito às condições inerentes aos concretos, isto é, aos processos. Cabia, assim, ao indexador definir quando um registro da literatura correspondia a uma informação indexável do assunto, ou seja, era função do indexador identificar no conteúdo dos documentos quais eram os possíveis concretos e processos, inerentes ao assunto, que poderiam servir pertinentemente à indexação. A análise dos assuntos era realizada com base nos nomes das coisas (entes) e com base naquilo que era dito sobre as coisas, semelhante à análise das proposições definidas por Aristóteles em seu tratado das Categorias.
Porém, diferentemente de Aristóteles, cujo objetivo se assentava na descrição do mundo dos seres sensíveis por meio de dez categorias fundamentais, das quais nove dessas categorias serviriam como predicados da categoria principal - a substância -, Kaiser trabalhou com apenas uma categoria (processo) para dar conta de identificar os aspectos que diziam respeito à sua categoria fundamental (concreto). Desse modo, todo o predicamento do concreto era realizado pelo(s) processo(s). A descrição a que Kaiser visava era de caráter muito mais específico e, pode-se dizer, se comparada a ambição de Aristóteles, muito mais modesto, pois tratava-se da descrição de assuntos de documentos especializados. O importante, aqui, é perceber que Kaiser, no anseio de desenvolver uma análise de assunto mais eficiente aos objetivos da indexação, baseada nas partes informativas dos assuntos, resgatou a noção de categorias preconizada filosoficamente por Aristóteles e introduziu, no universo do TTI, a análise por categorias, análise essa que, segundo Svenonius (2000), configuraria o curso da indexação do Século XX.

Vale ressaltar que não foram as categorias aristotélicas propriamente ditas de que Kaiser lançou mão em sua análise de assuntos, mas sim a 'noção de categorização'. Embora pareçam claras as semelhanças existentes entre a categoria concreto de Kaiser e a categoria substância de Aristóteles, bem como o processo de Kaiser e o fazer e o sofrer de Aristóteles, prefere-se, por ora, não esboçar uma relação direta entre tais categorias pois, ao que tudo indica, Kaiser imprimiu sua marca particular na definição de suas categorias ao se voltar aos aspectos que envolvem o mundo dos negócios, seu verdadeiro campo de abrangência.

Desse modo, e sob esse escopo técnico e especializado, Kaiser definiu suas categorias como: concretos - são os terms commodities, as coisas, os produtos, que, em termos mais teóricos, podem ser entendidos como os entes principais tratados em um discurso; processos são os terms of action, as ações, as atividades relativas às coisas, que, teoricamente, podem ser vistos como aquilo que incide sobre o concreto, aquilo que é proferido a respeito do concreto.

Uma outra categoria, pode-se dizer, complementar, foi definida por Kaiser para melhor especificar os concretos dos assuntos - a categoria países, ou lugares. Segundo o criador do systematc indexing, normalmente os assuntos especializados se referiam a algum commoditie (coisa, substância). As coisas podiam ser divididas em móveis (como equipamento, mobília, 
pessoas), imóveis (como rio, montanha, terreno) e abstratas (como trabalho, inteligência, sentimento).

Dentre as coisas imóveis, Kaiser deu especial atenção aos países, no sentido político e legislativo, ou seja, naqueles aspectos que dizem respeito aos habitantes, idiomas, costumes e leis. Assim, Kaiser estabeleceu outra classe de coisas expressas na literatura - os países. O bibliotecário alemão definiu, portanto, o universo das coisas em concretos (móveis, imóveis e abstratos) e países.

Definido o universo das coisas, era necessário dar conta daquilo que serviria de predicado para essas mesmas coisas, ou seja, era necessário estabelecer uma categoria que fixasse aquilo que é dito a respeito das coisas. Kaiser adotou, então, o termo processo para denotar as ações, que, numa orientação de cunho prático, pressuporia a localização do verbo no discurso. Diante disso, definiram-se as categorias: concreto país - processo, e a análise de assuntos, pela primeira vez no quadro teórico da indexação, passou a ser realizada por meio de categorias ontológicas previamente estabelecidas.

A análise de assunto de um documento que tratasse, por exemplo, das taxas tributárias de exportação dos produtos agrícolas brasileiros poderia, a partir desse momento, ser realizada com base na identificação das categorias:

- Concreto - Produto agrícola

- Lugar - Brasil

- Processo - Exportação

Um documento que abordasse questões realtivas à oscilação do dólar nos EUA, poderia ser tratado em termos de:

- Concreto - Dólar

- Lugar - EUA

- Processo - Oscilação

Por se tratarem de categorias preestabelecidas, obviamente que alguns questionamentos podem emergir. Por exemplo, os termos educação, comércio e produção são tratados por Kaiser como processos, como ações, numa perspectiva procedimental, e não fenomenal ou 'coisificada'. Então, em um assunto que tratasse a respeito do comércio de petróleo na Venezuela, seriam extraídas as categorias:

- Concreto - Petróleo

- Lugar - Venezuela

- Processo - Comércio

Ou, então, no assunto Lei para educação superior em Cuba, poderiam ser identificadas as seguintes categorias:
- Concreto - Lei

- Lugar - Cuba

- Processo - Educação superior

Muitos poderiam alegar que os termos comércio e educação superior descritos nos dois exemplos acima, tratam-se de concretos, visto que parecem ser de fato a coisa principal de que se fala. Porém, Kaiser preferiu privilegiar a dimensão dinâmica que termos como esses cumprem nos assuntos especializados, na medida em que refletem a substancialização de verbos que lhes dão origem (comercializar, educar).

A análise categorizada de Kaiser, que, arriscase afirmar, é uma combinação da análise pautada em componentes informativos idealizada por ele e por Otlet, com o modo aristotélico de analisar proposições, foi o marco inicial da concepção 'analítica' do método analítico-sintético retrabalhado, posteriormente, por Ranganathan.

\section{A dimensão analítica de Ranganathan}

A dimensão analítica desenvolvida por Ranganathan reflete toda preocupação e complexidade teóricas que sempre estiveram presentes em seu trabalho. Seu pragmatismo, diferente do de Kaiser, cujas explicações metodológicas tiveram um 'tom' mais de 'manual' a ser seguido, é fundamentado por um raciocínio teórico 'declarado' em suas inúmeras publicações. Tal fato, obviamente, não indica que esse seja mais ou menos importante que aquele, pelo contrário, o que se argumenta aqui é o pioneirismo de um e o aprofundamento teórico do outro.

Ranganathan buscou explicar o universo de assuntos a ser classificado de maneira bastante abrangente. Iniciou a explicação de sua teoria por meio da percepção humana, passando pela atualização conceitual (apercepção), até chegar ao mundo das ideias, do conhecimento e dos assuntos (ver Campos, 2001).

Salvaguardado o fato de que o universo a ser analisado por Kaiser se distingue do de Ranganathan pela abrangência, o primeiro de escopo técnico e especializado, o segundo de escopo enciclopédico e universal, não é descabido afirmar que ambos desenvolveram suas dimensões analíticas com base nos elementos que compõem os assuntos contidos nos conteúdos dos documentos. Já se observou que Kaiser desenhou seu caminho analítico tratando componentes informativos registrados como categorias, concepção aristotélica. Parte-se, agora, para a compreensão de como Ranganathan delineou a parte analítica de seu método.

O modo de classificar assuntos desenvolvido por Ranganathan foi pensado de modo a con- 
templar os planos ideacional (ideias), verbal (palavras e expressões) e notacional (códigos). Como qualquer esforço de classificação, as ideias advindas do pensamento, que são expressadas por meio da linguagem natural, são representadas por códigos (das mais variadas naturezas). Talvez, Ranganathan tenha sido de fato o teórico que mais se preocupou em explicar todo o movimento intelectual que envolve os três planos que dizem respeito ao processo de elaboração de classificações.

Cabe ressaltar uma importante diferença existente entre um sistema de indexação de mote alfabético e um sistema de classificação que se caracteriza por ser uma linguagem documentária notacional. No primeiro, os assuntos são representados por palavras/termos ou expressões terminológicas. Quando muito, lançase mão de codificações para fins de organização estrutural e funcional do sistema, como o fez Kaiser, ao atribuir códigos para arranjar e relacionar documentos e fichários. Nos sistemas de classificação os códigos são as representações diretas dos assuntos, ou seja, cumprem um papel primordial dentro da própria estrutura conceitual. Em outras palavras, a análise e a síntese de Kaiser não passa pelo plano dos códigos, que apenas servem para a execução do sistema como um todo, diferentemente da análise e da síntese de Ranganathan, cuja representação final recai sobre os códigos. Conforme esclarecido anteriormente, este estudo não está centrado em uma relação entre os sistemas desenvolvidos por ambos, mas sim entre os métodos (caminhos) por eles delineados.

Retornando à dimensão analítica de Ranganathan, concentra-se, agora, nos elementos que Ranganathan considerou serem os formadores dos assuntos compostos. Sua abordagem considera essencialmente dois elementos classificatórios, o assunto básico e a ideia isolada. O assunto básico corresponde, na maioria das vezes, às áreas mais abrangentes do conhecimento, sem nenhuma ideia isolada que o complemente. A ideia isolada corresponde a um componente de assunto, por si só não é um assunto, é um conceito. Em outras palavras, o passo inicial para a análise de um assunto é a identificação dos elementos de assuntos mais gerais e abrangentes (assuntos básicos) e dos elementos que os servem de complemento (ideias isoladas ou isolados).

Tanto as ideias básicas quanto as isoladas são tratadas com base em suas respectivas facetas, ou seja, são agrupadas por um termo genérico (a faceta) que será utilizado para a formação dos termos, e dos códigos, que representam os assuntos. Desse modo, as facetas que agrupam os assuntos básicos são as facetas básicas, e as que agrupam os isolados são as facetas isoladas.

Cada campo específico de saber tende a possuir suas próprias facetas, ou seja, seus próprios aspectos particulares. Por exemplo, o campo da Literatura poderia possuir como facetas: gênero literário, autor, obra, editor etc. Entendendo facetas como aspectos particulares de campos específicos, verifica-se que Ranganathan desenvolveu uma análise de assunto com base no agrupamento (por facetas) dos termos (tanto gerais quanto específicos) identificados como fundamentais para a representação de um assunto composto.

Ranganathan, aprimorando seu método sistemático, definiu o princípio das categorias fundamentais: Personalidade $(P)$, Matéria $(M)$, Energia (E), Espaço (S) e Tempo (T), conhecido como PMEST. Esse princípio zelava pela ordem de citação de concretividade decrescente, e passou a ser empregado a partir da quarta edição da Colon Classification. Embora Ranganathan tenha utilizado as categorias PMEST também com a finalidade de suprir insuficiências relativas à síntese de seu sistema, observa-se que tais categorias têm, também, importância capital na dimensão analítica, visto que, o próprio Ranganathan (1976), referente ao plano ideacional, afirmava que cada faceta de qualquer assunto devia ser considerada como uma manifestação de uma das cinco categorias fundamentais: Personalidade (objeto estudado), Matéria (materiais e substâncias), Energia (ações e processos), Espaço (local) e Tempo (época).

Vale lembrar que, semelhante ao contexto trabalhado por Kaiser (assuntos de documentos especializados), o contexto trabalhado por Ranganathan era os assuntos de documentos bibliográficos. Tanto Kaiser quanto Ranganathan buscaram tecer suas análises de assuntos de modo a não ficarem restritos apenas aos assuntos dos documentos mas, sim, aos aspectos fundamentais (categorias) do universo do conhecimento gerador dos assuntos. E nesse ponto, Ranganathan foi mais além, pois Kaiser generalizou que todos os assuntos técnicoespecializados poderiam ser tratados com base em concretos e processos, ao passo que Ranganathan, para além das categorias fundamentais, aprofundou sua classificação de assuntos aos níveis das facetas.

Enquanto o princípio geral de Kaiser definia que os conhecimentos, consequentemente, os assuntos, deveriam ser abordados em níveis de concretos e processos, Ranganathan definia 
que o universo de assunto deveria ser analisado do particular ao geral até se chegar a cinco ideias genéricas finais, indivisíveis e fundamentais. Essas ideias não possuíam valor de verdade ou falsidade, apenas de utilidade para fins de classificação. Portanto, não são definíveis, apenas supostas (Ranganathan, 1967). O critério ranganathiano pautado na utilidade classificatória é ressaltado por Aranalde (2009), que destacou a necessidade que se tinha de submeter a análise do universo (infinito) dos assuntos a termos mais gerais, possibilitando a classificação desse universo, quando materializado nos documentos bibliográficos.

Embora sejam as facetas os elementos efetivamente inovadores na metodologia ranganathiana, o presente estudo, quando relaciona Kaiser e Ranganathan, dirige o foco aos 'princípios gerais' definidos por ambos para a análise dos universos de conhecimento e de assunto. São os princípios gerais, traduzidos em uma concepção aristotélica de categorias, que são inerentes (ou estão presentes) no universo do conhecimento, refletidos nos assuntos comunicados. Por outro lado, as facetas estão presentes, ou melhor, são identificadas nos assuntos contidos nos conteúdos dos documentos. Isso se torna evidente diante do fato de que Ranganathan apresentou, nas edições da Colon Classification, uma série de "possíveis" facetas para cada área, e não uma descrição última e acabada daquelas que seriam as facetas correspondentes a cada assunto específico. Tal fato faria de seu sistema um esquema de classificação descritivo e não dinâmico.

Ranganathan elaborou regras que possibilitavam a criação de novas facetas, quando necessário. Portanto, as facetas estão presentes, e são evidenciadas, nos conteúdos dos documentos, e não necessariamente no universo do conhecimento. O que de fato está nos conhecimentos e nos assuntos em geral, são as categorias. Não se quer, com isso, afirmar que um conjunto de facetas não possa ser previamente atribuído aos campos de assuntos, mas, é inegável o fato de que cada documento bibliográfico possa trazer em seu conteúdo facetas não manifestadas anteriormente pelo próprio universo de assunto. Nesse sentido, tomam-se exemplos utilizados anteriormente, que ilustraram as categorias de Kaiser, no intuído de visualiza-los também na perspectiva de Ranganathan, exclusivamente no nível das categorias, que é o nível que os aproxima - o nível dos princípios gerais.

No caso de um documento cujo assunto aborde as taxas de exportação dos produtos agrícolas no Brasil, pode-se vislumbrar a seguinte análise:
- Personalidade (P) - Produto agrícola

- Energia (E) - Exportação

- Espaço (S) - Brasil

Cabe ressaltar que, os termos Produto agrícola, Brasil e Exportação são componentes que formam um assunto complexo e, que, agrupados por facetas, são manifestações das categorias $P$, E e $S$, respectivamente, da mesma forma que na análise de assunto de Kaiser são manifestações das categoria Concreto, Lugar e Processo. Nota-se que, o termo Produto agrícola é um termo composto que combina um assunto básico (Agricultura) uma ideia isolada (Produto). Sob a perspectiva de análise com base nas categorias PMEST, evidentemente, algumas informações a mais poderiam ser descritas. Por exemplo, se o documento abordasse de fato as taxas de exportação de produtos agrícolas no Brasil do século $X X$, a categoria referente ao aspecto temporal também se manifestaria na análise do assunto:

- Personalidade $(P)$ - Produto agrícola

- Energia (E) - Exportação

- Espaço (S) - Brasil

- Tempo (T) - Século XX

Da mesma forma, o documento cujo assunto seja a oscilação do dólar nos EUA no ano de 2014, poderia ser analisado assim:

- Personalidade (P) - Dólar

- Energia (E) - Oscilação

- Espaço (S) - EUA

- Tempo (T) - 2014

\begin{tabular}{|c|c|c|}
\hline Assunto & Kaiser & Ranganathan \\
\hline $\begin{array}{l}\text { Taxas de } \\
\text { exportação de } \\
\text { produtos } \\
\text { agrícolas no } \\
\text { Brasil do } \\
\text { século XX. }\end{array}$ & $\begin{array}{l}\text { Concreto: } \\
\text { Produto agrícola } \\
\text { Lugar: Brasil } \\
\text { Processo: } \\
\text { Exportação }\end{array}$ & $\begin{array}{l}\text { (P) Produto } \\
\text { agrícola } \\
\text { (E) Exportação } \\
\text { (S) Brasil } \\
\text { (T) Século XX }\end{array}$ \\
\hline $\begin{array}{l}\text { Oscilação do } \\
\text { dólar nos EUA } \\
\text { no ano de } \\
2014 \text {. }\end{array}$ & $\begin{array}{l}\text { Concreto: Dólar } \\
\text { Lugar: EUA } \\
\text { Processo: } \\
\text { Oscilação }\end{array}$ & $\begin{array}{l}\text { (P) Dólar } \\
\text { (E) Oscilação } \\
\text { (S) EUA } \\
\text { (T) } 2014\end{array}$ \\
\hline
\end{tabular}

Quadro 1. Análises de Kaiser e Ranganathan

Observando o quadro acima, nota-se uma correspondência entre as categorias: Concreto e Personalidade; Lugar e Espaço e; Processo e Energia. Faz-se necessário ponderar que Ranganathan, ao explicar, com assumida dificuldade, a categoria Personalidade, tomou um caminho distinto daquele argumentado por Kaiser. Esse, de maneira parecida com a de Aristóteles 
ao explicar sua categoria Substância, afirmou que tudo que for Processo diz respeito a alguma coisa (Concreto ou Lugar). Ou seja, assim como a análise aristotélica definia que todas as nove últimas categorias eram predicados da categoria principal (Substância), para Kaiser, a categoria principal de qualquer assunto é o Concreto, podendo, às vezes, haver um assunto que não contemplasse nenhum concreto, mas apenas lugares. Não havia sentido ter um Processo ocorrendo se não houvesse alguma 'coisa' sendo processada (ou processando). Assim como, para Aristóteles, todo predicado necessita de algum sujeito para existir, para Kaiser, todo processo pressupõe alguma coisa concreta e/ou espacial.

Ranganathan, numa perspectiva de análise por eliminação, afirmava em seu Prolegomena que toda faceta que não fosse manifestação ou de Matéria, ou de Energia, ou de Espaço, ou de Tempo, fatalmente seria uma manifestação de Personalidade. Porém, conforme apresentado anteriormente, o próprio Ranganathan (1967) afirmou que a Personalidade teria a ver com as entidades, com as coisas e tipos de coisas, guardando, assim, relação com o Concreto de Kaiser. Independentemente do fato de o indiano ter trilhado outro caminho para se chegar à suposição de sua Personalidade, o fato é que, na análise propriamente dita, concretos e personalidades cumprem papeis parecidos para a compreensão e definição dos assuntos complexos.

Nas correspondências existentes entre Lugar e Espaço e, entre Processo e Energia, parece não haver lugar a dúvidas quanto às reciprocidades, pois a primeira nitidamente diz respeito aos aspectos espaciais e a segunda às ações e operações.

Obviamente, por se tratarem de princípios gerais (maiores termos genéricos possíveis) e, como ressaltou Ranganathan (1967), por se tratarem de categorias fundamentais indefiniveis (pois são apenas supostas), a categorização não garante uma análise uniforme, isenta de variações. Mas, garante uma direção, uma forma de analisar.

Independentemente das naturezas das categorias se diferenciarem quanto à perspectiva categorias semânticas no caso de Kaiser (Svenonius, 2000), categorias ontológicas no caso de Ranganathan (Aranalde, 2009) - o fato é que o pragmatismo (método) utilizado por ambos ao desenvolverem as análises dos assuntos é semelhante: analisar discursos com base em seus elementos constituintes fundamentais, ou seja, analisar assuntos com base em categorias predeterminadas.
Essa forma de analisar, baseada na identificação de 'aspectos elementares' dos universos de conhecimentos e de assuntos, 'cristalizados por categorias', consiste na dimensão analítica do método analítico-sintético.

\section{A dimensão sintética em Kaiser e em Ranganathan}

A análise nas obras de Kaiser permitiu a definição dos pontos de observação utilizados para o estudo, que são os aspectos fundamentais dos métodos de Kaiser e de Ranganathan, a saber: a) os elementos que compõem a análise; b) a realização da análise; c) a realização da síntese e; d) os produtos da síntese.

O significado da palavra sintético está relacionado tanto com o ato de 'operar das partes para o todo', 'unir elementos', quanto com a 'artificialidade' de tal operação. Ou seja, os dicionários de língua portuguesa dão a clara dimensão de que sintético é o adjetivo relacionado à ação de unir componentes de maneira artificial. Embora, numa perspectiva filosófica, tanto analítico quanto sintético sejam termos introduzidos por Kant para investigar validades de proposições dependentes de fatos, levando em conta juízos explicativos e extensivos (Abbagnano, 2008), aos objetivos do presente estudo, a concepção etimológica da palavra grega synthetikós, fornecida pelos dicionários, é suficiente para a investigação das sínteses desenvolvidas por Kaiser e por Ranganathan. Aspecto que torna plausível essa decisão investigativa é o fato de que o argumento da presente pesquisa se sustenta na compreensão dos caminhos pragmáticos percorridos por Kaiser e Ranganathan, ou seja, na compreensão dos métodos por eles criados para sintetizar suas respectivas análises. Nesse sentido, a relevância está em "como" ambos uniram artificialmente seus assuntos decompostos em categorias, e não no julgamento da validade de suas declarações de assuntos.

Assim, compreender as sínteses de Kaiser e de Ranganathan requer direcionar a atenção aos caminhos por eles tomados quando procuraram solucionar a representação padronizada de suas análises de assunto, ou seja, direcionar o foco ao pragmatismo de ambos no que se refere à eficiência da construção das declarações de assuntos. Nesse sentido, a presente seção explicita como Kaiser e Ranganathan teceram seus métodos no que tange à recomposição dos assuntos analisados em seus componentes constituintes, mais especificamente, em suas categorias. Desse modo, analisaram-se as 'reorganizações de informações de assuntos' promovidas pela indexação de Kaiser e pela classi- 
ficação de Ranganathan. Vale ressaltar que, embora a síntese de Ranganathan esteja, em última instância, em suas codificações, o que mais interessa ao presente estudo é a forma como ele utilizou seus princípios mais genéricos (as categorias) para dar rumo à sua síntese.

Kaiser $(1908 ; 1911)$ empregou o termo statement para designar a declaração ou cabeçalho de assunto de seu sistema. Para o bibliotecário alemão, os statements eram, essencialmente, expressões verbais padronizadas, compostas por termos que manifestavam as categorias concreto (e localidade) e processo, nos assuntos analisados. Em outras palavras, os statements consistiam na representação das informações mais relevantes extraídas dos assuntos dos documentos, tomando por base os aspectos estáticos (coisas - analisadas em nível de concretos) e os aspectos dinâmicos (aquilo que incide sobre as coisas - analisado em nível de processos).

Se, para o entendimento da dimensão analítica do sistema de Kaiser o foco esteve direcionado à compreensão das categorias, para o entendimento da dimensão sintética a atenção voltarse-á ao modus operandi da construção dos índices, pontualmente no desenvolvimento dos statements, afinal, foi por meio deles que Kaiser procurou estabelecer como os assuntos analisados poderiam ser padronizadamente enunciados. Para Kaiser, existiam três possíveis combinações para a construção dos statements: 1) concreto - proceso; 2) país - proceso; 3) concreto - país - processo.

- Exemplo 1: Produto agrícola - Exportação

- Exemplo 2: Brasil - Exportação

- Exemplo 3: Produto agrícola - Brasil - Exportação

Verifica-se que a ordem de importância definida por Kaiser privilegia a concretividade dos aspectos dos assuntos, privilegia aquilo que é mais estático, aquilo que é 'coisificado' (no sentido ontológico do termo). Observa-se que a categoria concreto (quando existir no assunto) sempre estará em posição privilegiada se comparada com as categorias país (lugar) e processo. Nota-se, ainda, que as categorias que designam coisas (concreto e país) sempre irão figurar como termos de entrada na ordem de citação estabelecida por Kaiser. Assim, evidencia-se que a ordem de citação pautada na sequência de 'concretividade decrescente', adotada por Ranganathan somente na década de 1950, quando da adoção das categorias PMEST na quarta edição da Colon Classification, já havia sido utilizada por Kaiser no Systematic Indexing.
Porém, faz-se necessário um 'parêntese' para explicar as perspectivas distintas entre as noções de concretividade de Kaiser e de Ranganathan. A concretividade no sistema de Kaiser está relacionada com o quão estático pode ser um elemento de assunto. Identificado o elemento mais estático do assunto, todas as demais informações diriam respeito a esse elemento (concreto). Para Ranganathan, o elemento mais concreto pode surgir de uma relação de causa e efeito. Conforme destacado por Aranalde (2009), para o bibliotecário indiano, a causa (o porquê) muitas vezes pode ser mais concreto que o próprio efeito (o o quê). Por exemplo, um artigo que trate sobre indexação. Indexação pode ser entendida como um efeito dos fazeres da Biblioteconomia, que seria sua causa. Desse modo, a área de conhecimento Biblioteconomia seria mais concreta que a própria indexação. Embora a noção de concretividade de Kaiser esteja pautada na relação entre estático e dinâmico e a de Ranganathan esteja ligada à relação entre causa e efeito, o fato é que ambos buscaram privilegiar aquilo que há de mais concreto nos assuntos, a fim de ditarem a ordem de importância de suas sínteses.

Retornado à síntese de Kaiser, há que se ressaltar que os termos que compunham os enunciados de Kaiser não eram elementos isolados que por si próprios traziam informações independentes a respeito de um assunto, eram termos conectados uns com os outros que faziam referência à mesma informação, sendo o concreto o termo principal (substancial), o processo a ação, ou condição, do concreto e, o país a localidade em que a ação ocorria. Portanto, os três termos juntos compõem uma espécie de esqueleto da informação, ou seja, compõem o enunciado (declaração) do assunto.

Reportando-se às três combinações estabelecidas por Kaiser, é possível verificar um aspecto não explicitado antes na dimensão analítica. Ao notar que Kaiser não contempla uma combinação do tipo concreto - país, verifica-se que a categoria país necessariamente se refere ao local em que a ação ocorre, visto que a combinação país - processo está prevista por Kaiser. Desse modo, é possível complementar o entendimento da categoria país ressaltando que tal categoria jamais se referirá ao local em que o concreto está, mas sim, ao local em que o processo ocorre.

Assim como qualquer iniciativa de representação do conhecimento, o enunciado de Kaiser não definia a informação completa sobre o assunto de um documento, mas, definia os elementos que necessitavam ser conectados para a obtenção das informações relevantes sobre o 
assunto. A esse respeito, Kaiser determinou em sua síntese a possibilidade de amplificações (ou ampliações) dos enunciados, de forma a viabilizar a inclusão de elementos não contemplados em um único enunciado de combinação padrão, conforme exposto acima. Para tanto, adotou o termo amplification para se referir a um suplemento do statement. A amplificação consistia em algumas extensões do enunciado. Enunciado e extensão juntos tendiam a cobrir a informação mais completa possível referente a um concreto. Os tipos de amplificação definidos por Kaiser foram: a extensão, as datas e os autores. Desse modo, Kaiser $(1911, \S 305)$ tabulou as partes de uma informação da seguinte maneira:

\begin{tabular}{ll}
\hline Statement & Concrete \\
\hline & Country \\
\hline Amplification & Process \\
\hline Extension \\
\hline Dates \\
\hline
\end{tabular}

Quadro 2. Partes de uma informação (Kaiser, 1911)

Apresentar os aspectos que aproximam a dimensão sintética de Ranganathan com a de Kaiser, julga-se necessário apresentar alguns aspectos que particularizam Ranganathan na dimensão sintética, aspectos, esses, que avançaram significativamente a representação de assuntos no universo do tratamento temático da informação. É de amplo conhecimento o fato de que a contribuição de Ranganathan reside muito mais no quadro teórico da organização do conhecimento do que na prática das classificações de documentos de bibliotecas. Ou seja, o método analítico-sintético, fio condutor de sua classificação facetada, tornou-se mais visível que a própria Colon Classification, que, na pior das hipóteses, foi o grande instrumento de aplicação e de experimentação de Ranganathan quando do aprimoramento de sua teoria metodológica. Desse modo, procura-se destacar o avanço de Ranganathan na dimensão sintética, e sua aproximação com a síntese de Kaiser, tendo em vista o pragmatismo do indiano quando da construção de suas representações de assuntos compostos e ou complexos.

Mesmo tendo em conta que a síntese de Ranganathan (notação classificatória) resulte em produto distinto da síntese de Kaiser (enunciado alfabético), torna-se possível relacionar ambas as sínteses no que se refere ao pragmatismo (caminho) desenvolvido pelos teóricos. Ranganathan percebeu que seu esquema de classificação apresentou mudanças significativas ao longo dos anos, fato que o levou a distingui-lo em duas fases: a fase do esquema rigidamente facetado e a fase do esquema livremente facetado.

O esquema rigidamente facetado era constituído de tabelas de assuntos principais, tabelas de assuntos secundários (subdivisões comuns e auxiliares especiais) e regras rígidas sobre a ordem de citação dos conceitos. Isto é, tanto as facetas quanto a ordem de representação das facetas eram predeterminadas para cada classe de assuntos, cristalizadas pelas chamadas fórmulas facetadas (Campos, 2001). A fórmula facetada (pré)estruturava cada área de conhecimento. Essa estrutura prefixada pela fórmula facetada se assemelha à estrutura prefixada dos enunciados de Kaiser, não somente por definir a ordem de citação, mas, principalmente, por tal ordem ser determinada pela concretividade decrescente. Embora cada classe de assunto apresentasse uma fórmula própria, a orientação preconcebida para a combinação dos conceitos identificados na análise foi um aspecto preconizado por Kaiser.

No entanto, Ranganathan avançou a questão da síntese de assuntos em prol de uma classificação de assuntos que efetivamente respeitasse a dinamicidade do conhecimento. Tentar prever a ordem mais adequada para a síntese dos assuntos não era uma boa maneira de acompanhar o caráter expansivo do universo do conhecimento. Assim, Ranganathan, rompendo com a rigidez de seu esquema classificatório, a partir da quarta edição da Colon Classification (1952), abandonou o princípio da fórmula facetada e, de certa forma, delegou a definição da ordem de importância dos conceitos na síntese aos utilizadores do sistema. A partir desse momento, o esquema de Ranganathan passou a ser considerado, por ele mesmo, como um esquema livremente facetado, ou analítico sintético, pois não determinava mais a ordem para a combinação dos conceitos. A combinação passou a ser conduzida por princípios, o que possibilitava a criação de novas subdivisões.

No que se refere às atualizações dos conhecimentos e dos assuntos, Kaiser, embora não tenha avançado tanto nessa questão quanto Ranganathan, também não as negligenciou. Mesmo não abandonando as combinações predeterminadas das categorias que compunham os enunciados, o bibliotecário alemão, por trabalhar com linguagem alfabética, flexibilizou a rigidez de sua síntese ao abrir espaço para as amplificações que complementavam os enun- 
ciados. Desse modo, peculiaridades características dos assuntos especializados, não contempladas pelas categorias, podiam ser incluídas na síntese dos assuntos. Nesse quesito, Ranganathan ampliou a flexibilidade de sua síntese não com elementos complementares, mas sim com aspectos estruturais, que deram maior liberdade à própria construção das notações. Notadamente, Ranganathan foi quem efetiva- mente desenvolveu uma teoria de classificação de assuntos de base dinâmica, criando preceitos de flexibilidade e de hospitalidade que permitiam a atualização da própria organização dos assuntos. No entanto, evidencia-se, aquí, as semelhanças entre os caminhos (pragmatismos) delineados por ambos os bibliotecários ao tecerem seus métodos. O quadro 3 permite uma visualização sucinta desse pioneirismo.

\begin{tabular}{|c|c|c|c|c|}
\hline & & & & \\
\hline & \multicolumn{4}{|c|}{ Pragmatismo } \\
\hline & $\begin{array}{l}\text { Componentes da } \\
\text { análise }\end{array}$ & Realização da análise & $\begin{array}{l}\text { Realização da } \\
\text { sintese }\end{array}$ & Produto da síntese \\
\hline \multirow[t]{2}{*}{ Kaiser } & $\begin{array}{l}\text { Palavras da literatura } \\
\text { indexável }\end{array}$ & $\begin{array}{l}\text { Decomposição dos } \\
\text { assuntos em suas } \\
\text { partes constituintes } \\
\text { (categorias) }\end{array}$ & $\begin{array}{l}\text { Recomposição dos } \\
\text { assuntos por meio da } \\
\text { construção de } \\
\text { declarações verbais } \\
\text { orientadas pela }\end{array}$ & $\begin{array}{l}\text { Enunciado e } \\
\text { amplificação }\end{array}$ \\
\hline & $\begin{array}{l}\text { Plano ideacional e } \\
\text { plano verbal }\end{array}$ & $\begin{array}{l}\text { Plano ideacional e } \\
\text { plano verbal }\end{array}$ & $\begin{array}{l}\text { concretividade das } \\
\text { categorias de análise }\end{array}$ & Plano verbal \\
\hline \multirow[t]{2}{*}{ Ranganathan } & $\begin{array}{l}\text { Conceitos das áreas } \\
\text { de assunto }\end{array}$ & $\begin{array}{l}\text { Decomposição dos } \\
\text { assuntos em suas } \\
\text { partes constituintes } \\
\text { (facetas e categorias) }\end{array}$ & $\begin{array}{l}\text { Recomposição dos } \\
\text { assuntos por meio da } \\
\text { construção de } \\
\text { declarações } \\
\text { notacionais }\end{array}$ & $\begin{array}{l}\text { Notação } \\
\text { classificatória }\end{array}$ \\
\hline & $\begin{array}{l}\text { Plano ideacional e } \\
\text { plano verbal }\end{array}$ & $\begin{array}{l}\text { Plano ideacional e } \\
\text { plano verbal }\end{array}$ & $\begin{array}{l}\text { orientadas pela } \\
\text { concretividade das } \\
\text { categorias de análise }\end{array}$ & Plano notacional \\
\hline
\end{tabular}

Quadro 3. Aproximação dos pragmatismos de Kaiser e de Ranganathan

Entendendo o pragmatismo como um meio (e não como um fim), é possível visualizar o Quadro 3 como se fosse a ilustração de dois sistemas, o sistema de Kaiser e o sistema de Ranganathan. Os componentes da análise são os elementos de entrada em ambos os sistemas. Esses elementos passam pelas realizações da análise e da síntese, que consistem nos meios dos sistemas, para chegar aos produtos finais, ou melhor, aos elementos de saída dos sistemas (produto da síntese). Têm-se, portanto, dois sistemas compostos por entradas, meios e saídas. Embora, tanto as entradas quanto as saídas sejam conceitualmente distintas nos sistemas observados, ambas as sistemáticas apresentam claras semelhanças quanto aos meios de se chegar ao produto final. Desse modo, são nas formas de realização da análise e de realização da síntese que se encontram as interseções fundamentais entre o pragmatismo de Kaiser e o pragmatismo de Ranganathan.

Ambos os bibliotecários realizam suas análises por meio da decomposição dos assuntos em suas partes constituintes, transitando entre o plano ideacional, que define e ou supõe as ca- tegorias de análise e, o plano verbal, que dá os contornos terminológicos às ideias contidas nos assuntos. Para a realização da síntese, ambos reapresentam os assuntos por meio da recomposição dos mesmos pautada na construção de declarações de assuntos (verbal, no caso de Kaiser e, notacional, no caso de Ranganathan), cujas ordens de importância são orientadas pelo grau de concretividade que as categorias de análise apresentam. Assim, verifica-se que, mesmo Kaiser apresentando como produto de seu método uma declaração verbal e Ranganathan apresentando como produto uma declaração notacional, o fato é que ambos trataram seus elementos de entrada de maneira fundamentalmente semelhante. Desse modo, sustenta-se o argumento de que Kaiser, entre os anos de 1908 e 1911, já havia definido e publicado os pilares do método analítico-sintético. Kaiser o fez para a elaboração de um método de construção de índices sistemáticos. Ranganathan, entre as décadas de 1930 e 1960, utilizou o mesmo pragmatismo para a elaboração de um método de construção de esquemas de classificação. Em outras palavras, Kaiser fez surgir a construção de índices analítico-sintéticos e, 
posteriormente, Ranganathan fez surgir a construção de classificações analíticas-sintéticas.

\section{Conclusões}

Um olhar investigativo sobre as obras e ideias de Kaiser permitiu a identificação de duas dimensões teóricas, contidas em sua indexação sistemática, que proporcionaram a definição dos pontos de observação que serviram de elementos de inferência do presente estudo: a dimensão analítica, cujos pontos de observação foram os elementos da análise e a realização da análise e; a dimensão sintética, cujos pontos de observação foram a realização da síntese e os produtos da síntese. Com uma abordagem especialmente voltada à realização da análise e à realização da síntese, pois são os pontos que melhor traduzem os pragmatismos de Kaiser e de Ranganathan, foi possivel relacionar os métodos desenvolvidos por ambos os bibliotecários.

Constatando-se que Kaiser e Ranganathan pautaram a realização de suas análises na decomposição dos assuntos em suas partes constituintes, baseadas em princípios gerais (categorias) e, realizaram suas sínteses pautadas na recomposição dos assuntos por meio de orientações também guiadas pelos mesmos princípios gerais (categorias) utilizados na análise, inclusive o privilégio dado à concretividade de cada categoria, levantaram-se os elementos que sustentam a tese de que Kaiser foi o pioneiro do método analítico-sintético. Ao desenvolver um método para a construção de índices sistemáticos baseados na união dos movimentos de analisar e de sintetizar assuntos, com base em categorias e em regras predeterminadas, Kaiser, em 1911, deu origem ao método que serviria de base para Ranganathan, a partir da década de 1930, desenvolver sua teoria de classificação facetada. Corrobora-se, assim, a afirmação de Svenonius (2000) de que Kaiser teria introduzido o método analítico-sintético quando combinou análise de assunto com a reorganização da informação de acordo com regras altamente estruturadas, afirmação, essa, que inspirou a proposição do presente estudo.

Porém, aqui, lançou-se mão de abordagem metodológica pautada no pragmatismo para investigar 'como' essa análise de assunto e essa reorganização da informação preconizadas por Kaiser serviram de base para a concepção do método analítico-sintético. $O$ resultado da investigação, realizada nas dimensões analíticas e sintéticas dos métodos desenvolvidos por ambos os bibliotecários, com ênfase nos pragmatismos das realizações da análise e da síntese, fornece, ao nosso ver, subsídios consistentes de que Kaiser foi, do ponto de vista pragmático, o precursor do movimento analíticosintético.

\section{Notas}

O presente trabalho fundamenta-se na tese de doutorado defendida por Rodrigo de Sales na Universidade Estadual Paulista (UNESP), sob a orientação do Prof. Dr. José Augusto Guimarães. A tese, em seu inteiro teor, foi publicada em forma de livro em 2014.

\section{Referências}

Abagnano, N. (1998). Dicionário de filosofia. 2.ed. Tradução de Alfredo Bosi. São Paulo: Martins Fontes, 1998.

Aranalde, M. M. (2009). Reflexões sobre os esquemas categoriais de Aristóteles, Kant e Ranganathan. // Ci. Inf. 38:1 (jan./abr. 2009) 86-108.

Aristóteles (2010). Categorias. 2 ed. Tradução [do grego clássico] de José Veríssimo Teixeira da Mata. São Paulo: Martim Claret, 2010. (Coleção a obra prima de cada autor, 305).

Blau, J. L. (2006). Introdução. // James, W. Pragmatismo. Tradução de Jorge Caetano da Silva. São Paulo: Martin Claret, 2006. 13-22.

Campos, M. L. de A. (2001). Linguagem documentária: teorias que fundamentam sua elaboração. Niterói: EdUFF, 2001.

Dutra, L. H. de A. (2008). Pragmática da investigação científica. São Paulo: Loyola, 2008.

Foskett, A.C. (1973). A abordagem temática da informação. Tradução de Antônio Agenor Briquet de Lemos. São Paulo: Polígono; Brasília: Ed.UnB, 1973.

Hessen, J. (1987). Teoria do Conhecimento. 8. ed. Tradução de António Correia. Coimbra: A. Amado, 1987.

James, W. (2006). Pragmatismo. Tradução de Jorge Caetano da Silva. São Paulo: Martin Claret, 2006.

Kaiser, J. O. (1911). Systematic indexing. London: Isaac Pitman \& Sons, 1911. (The Card System Series, 2).

Kaiser, J. O. (1908). The card system at the office. London: Vacher \& Sons, 1908 (The Card System Series, 1).

Lalande, A. (1999). Vocabulário técnico e crítico da filosofia. 3.ed. Tradução de Fátima Sá Correia et al. São Paulo: Martins Fontes, 1999.

Ranganathan, S. R. (1976). Colon classification. 6. ed., 4. reimpr. Bombay; Calcutta; New Delhi; Madras; Lucknow; Bangalore; London; New York: Asia Publishing House, 1976.

Ranganathan, S. R. (1967). Prolegomena to library classification. Bombay: Asia Publishing House, 1967.

Sales, R. (2014). A organização da informação de Julius Kaiser: o nascimento do método analítico-sintético. Saarbrücken: Novas Edições Acadêmicas/OmniScriptum GmbH \& Co., 2014

Svenonius, E. (2000). The intellectual foundation of information organization. Cambridge: MIT Press, 2000.

Enviado: 2014-02-14.

Aceptado: 2014-06-09. 